\title{
A REGIONAL ANALYSIS OF URBAN POPULATION AND TRANSPORT ENERGY CONSUMPTION
}

\author{
Houshmand E. Masoumi ${ }^{1}$, Hamid Soltanzadeh ${ }^{2}$ \\ ${ }^{1,2}$ Center for Technology and Society, Technical University of Berlin, Berlin, Germany \\ Received 29 July 2014; accepted 27 August 2014
}

\begin{abstract}
The association between urban population density and transport energy consumption is a well-discussed topic in the metropolitan level. However it is less studied in the regional scale. This paper demonstrates the results of an observation about transport energy use in 174 regions of Iran. Logarithmic regression analysis shows very weak associations between urban population density and transport fuel use in the regional level. However statistical analysis of population size and the area of the regions by means of Kruskal-Wallis test indicates that regions with medium populations of between 100000 and 500000 inhabitants and areas of between 2000 and 5000 square kilometers enjoy more energy-efficient consumption than regions with more than 500000 people and 15000 square kilometers area and small regions of less than 100000 residents and 2000 square kilometers. This observation raises the question about higher energy efficiency of mid-sized cities and regions. Also more specialized studies about urban sprawl and its impacts on transport energy consumption in small towns and rural places seem desirable.
\end{abstract}

Keywords: regional planning, urban population density, car dependence, transport energy consumption, urban form, Iran.

\section{Introduction}

The effects of the built environment on transport fuel use has been subject to several studies, most of which suggest that more compact urban forms can possibly limit ever increasing energy use accelerated by jumping auto dependency rates. This acquisition has almost been proven to be significant in determining urban sustainability. It is noteworthy that the majority of such studies target city level and the larger scales such as regions have drawn less attention. This paper takes the same approach that is employed in recent city-level researches, but analyzes the urban population in the regional level. 174 regions of Iran are selected to be studied. Given the urban and rural populations are separately measured in the Iranian censes, there is good ground for examining the regional aspects of urban transport energy use. In the first part, the paper investigates regional significance of the accepted notions about effectiveness of urban density on energy use. The first objective is to check if there are associations between urban population densities of the regions and their transport fuel consumption, like the correlations that are seen in case of cities. Then two other important measures, namely urban population sizes of the regions as well as regional area, are tested. The second

${ }^{1}$ Corresponding author: masoumi@ztg.tu-berlin.de 
objective is to check if transport energy consumption is significantly different in regions with different urban population sizes and areas.

\section{Urban Form and Transport Energy Consumption}

Testing the correlations between urban form including density and size on the one hand and transport energy use on the other hand has been subject of a continuous academic and practical debate which dates back to three decades ago. Studying the effects of built environment on mobility started in 1950 s and 1960s. Later the energy concerns were added to the related research topics after the 1970s' energy crisis. A turning point has been the long-term work of Newman and Kenworthy that made a wave of advocacy and critiques. Their primary study (1989) targeted the urban form and car dependence in 32 world cities situated in North America, Australia, Europe, high-income Asia, and low-income Asia. Their renowned research found negative correlation between urban density and transport-related gasoline use. Such an impact is a consequence of auto dependence in several observed cities mostly visible in the US, Canada, and Australia. Newman and Kenworthy's study had undeniable influence on both academics and policy makers. The effects of their work on urban policies of 1990s in some European countries are apparent as Breheny (1995) lists some of them (such as Commission of the European Communities, 1990; Department of the Environment, 1990, 1992, 1993, 1994; National Physical Planning Agency, 1991). Nevertheless the criticisms in academia led to a long-term debate which lasts until today.

The critics target the technique and/or the philosophy of Newman and Kenworhy's work. A group of scholars believe that compactness cannot have a fundamental role in weakening auto use and therefore fuel consumption compared to other factors such as historical, cultural, and socioeconomic differences as well as economic issues (Gordon and Rishardson, 1989; GomezIbanez, 1991; Kirwan, 1992); or at least it is difficult or impossible to reverse the decentralization trend and direct it toward implementation of compactness (Breheny, 1995). The general effectiveness of compact city in solving urban sprawl problems has also been questioned by Neuman (2005). The scholars who point technical shortcomings in 1989's study include Brindle (1994) who noted incorrectness of graphing to per capita parameters (transport energy use per capita urban land per capita). Later Evill (1995) and Bourdic and Salat (2011) rejected the existence of the spurious correlation. In return, more sets of cities from different regions including North America, Australia/ New Zealand, high-income and low-income Asia, Europe, and Latin America, and the Middle East (including Tehran) were studied by Kenworthy and Laube. They firstly examined 46 cities (1999a; 1999b) and then 84 cities (2003) and managed to react to a number of criticisms. A point in their reply that is important for our study is that the wealth of cities does not have any significant effect on car use and consequently transport fuel use. Furthermore some wealthier cities enjoy higher public transport share because they invest more on public transit systems.

Reduction in energy use as a result of densification has been repeated in newer studies (Hester, 2006; Gilbert and Pearl, 2010). Also the significant multivariate correlation of private transport energy use and urban density was shown by means of fractal theory (Bourdic and Salat, 
2011). After 25 years of debate, there are still doubts about the mechanisms of the effects of density, city size, and sprawl on transport energy use. The points that are still in doubt are the energy use impacts of social aspects in large cities as well as city size and household income. To control for some of the unwanted bonuses of economy and culture, some scholars such as Peter Naess $(1993,1995)$ studied 22 Scandinavian cities instead of cities from all over the world. He found that city size and density are important on defining per capita transport energy consumption. Also a number of Japanese scientists have done the same for Japanese cities to test the impacts in their home country (Nakamura and Horiike, 2002; Ogawa and Yamada, 2002). Limiting the study to a region with uniform socioeconomic trends seems a logical approach and can help omit a number of cultural and economic dissimilarities among different countries of the world.

\section{Methodology}

The first objective of the paper is to find possible correlations between urban population density and transport energy use in the regional level. 174 Iranian counties (Shahrestan) are selected to make a logarithmic regression. "Shahrestan" which is similar to "county" in the US, is a boundary smaller than province and larger than city. The data including population, area, and transport energy consumption are derived from Iranian 2011 official census. As seen in Fig. 1, the distribution of the selected areas is so that they cover most of sub-cultures and sub-climates of Iran. Another criterion for selecting the urban areas has been providing different urban sizes. The sample contains large metropolitan areas like Mashhad and Esfahan as well as very small settlements. Also the economic conditions are different in the selected "Shahrestans". However two important parameters are controlled for: car price and fuel price. These are uniform throughout the country, therefore good research condition is provided to test the validity of other factors such as density, population size, and area.

One reason for taking "Shahrestan" as the basis of study instead of city has been because of lack of necessary data in the city level in Iran. The ten-year Iranian general censes do not cover cities, while smaller or larger administrative limitations are included in them. Instead "Shahrestan" is an important statistical boundary, and collection of city-level data remains for municipalities and other governmental organizations. As a consequence, one or more cities are located in each "Shahrestan". This data shortcoming has led this study to have a regional nature. In other words, instead of cities, urban population and concentration of urban areas are discussed in this study. Nevertheless a useful point is seen in the official data; the population is divided into urban and rural categories. Therefore the urban population of each region is accessible. The most important characteristics of the study regions such as urban population, area, and annual transport energy use are illustrated in Fig. 2, 3, and 4. As seen in these figures, very populated or very large regions are included in the observation, which adds to the diversity of the selected sample. 


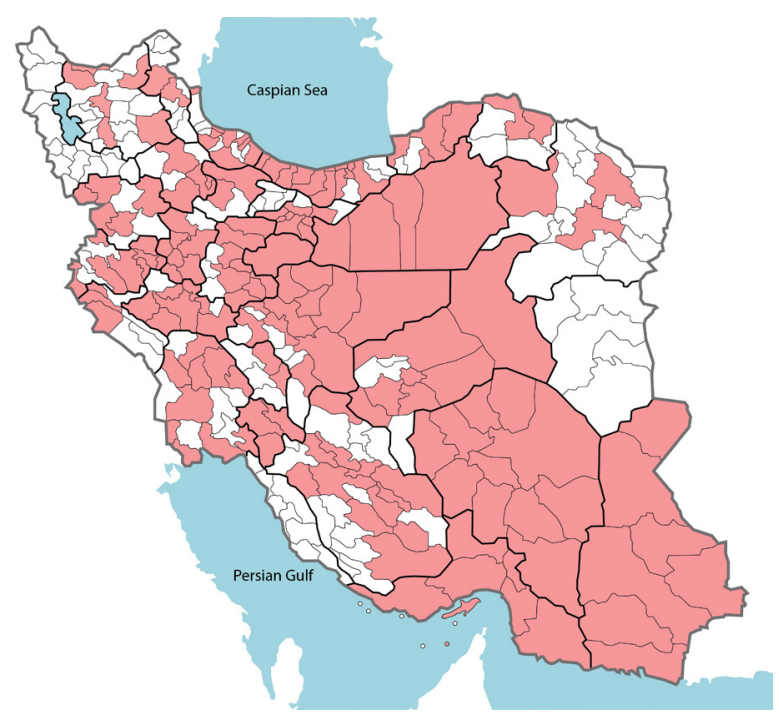

Fig. 1.

Presentation of the Location of the Case-Study Regions in Iran

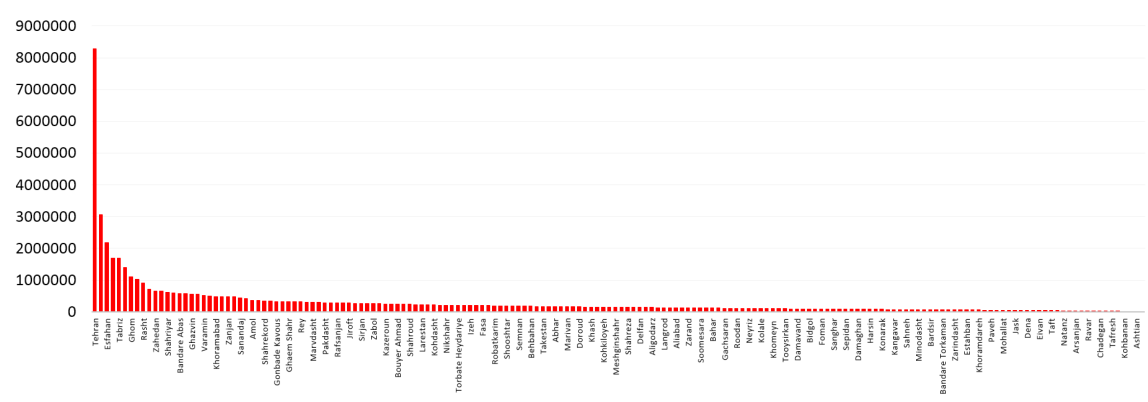

Fig. 2.

2011 Urban Population of 174 Selected Iranian Regions

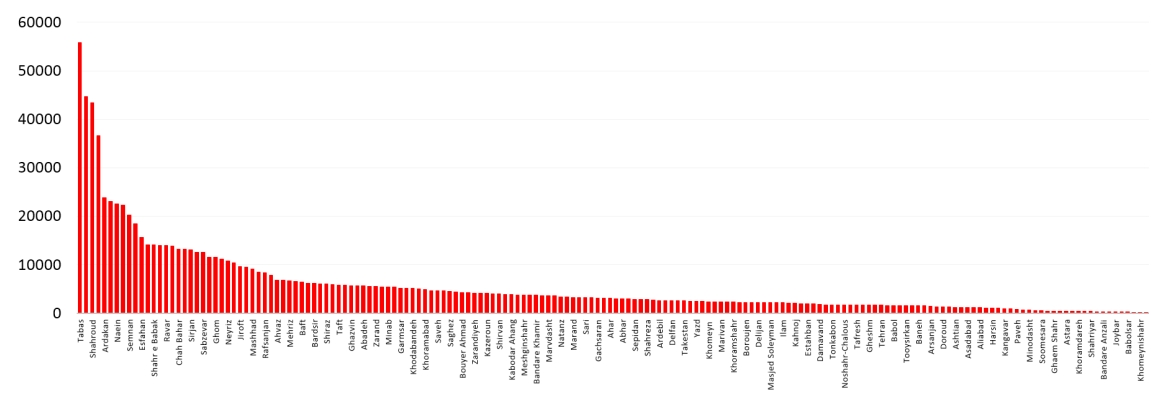

Fig. 3.

Areas of 174 Iranian Regions ( $\mathrm{km} 2$ ) 


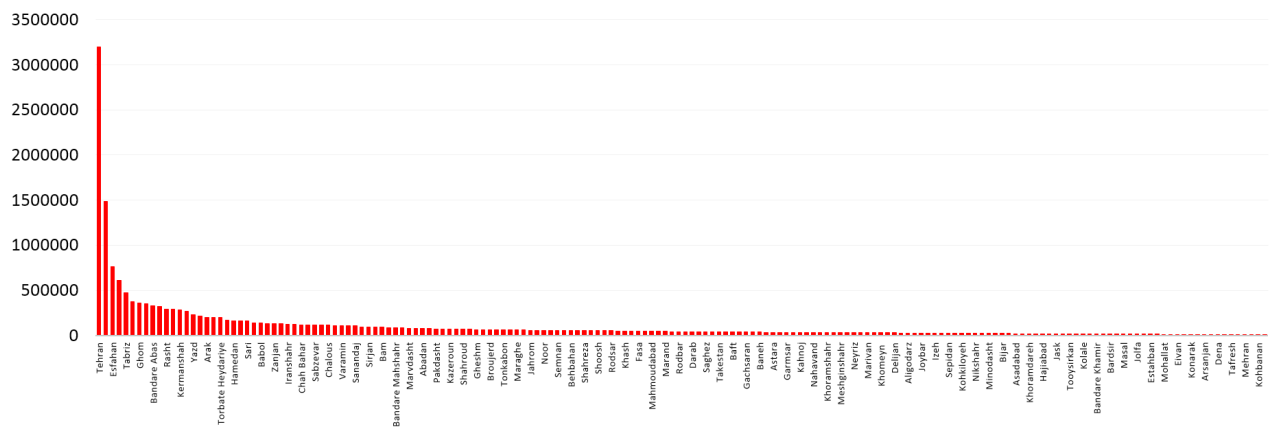

Fig. 4.

Transport Energy Consumption $\left(m^{3}\right)$ in 174 Selected Iranian Regions

Table 1

Sample Descriptive Stats

\begin{tabular}{l|l|llll}
\hline Stat. & No. & Average & Min & Max & St. Dev. \\
\hline Population & & 300708 & 5263 & 8293140 & 711767 \\
Area $\left(\mathrm{km}^{2}\right)$ & & 5538 & 69 & 55808 & 7811 \\
Urban population density (per/skm) & 174 & 159 & 1,24 & 5079 & 464 \\
Transport energy use $\left(\mathrm{m}^{3}\right)$ & & 104215 & 589 & 3201230 & 279269 \\
Transport energy use per year per capita $\left(\mathrm{m}^{3}\right)$ & & 0,354 & 0,043 & 3,210 & 0,307 \\
\hline
\end{tabular}

To examine the correlation between urban population densities of the selected regions with transport energy use per year per capita, these two figures are put into a single diagram like the one developed by Newman and Kenworthy. To avoid the Brindle's spurious correlation, only one the horizontal and vertical parameters is "per capita”, regardless of correctness of his claim. The two parameters are "urban population density of the regions" on the horizontal axis and "transport energy consumption per year per capita” on the vertical axis. Table 1 shows the descriptive statistics of the selected regions. The average population is 300708 people accommodated in an average of 5538 square kilometers, which gives an urban population density of 159 persons per square kilometer.

The second objective is to compare transport fuel use in different urban population sizes and regional areas. To do this, the regions are divided into different categories. In case of urban population size, the regions are grouped as follows: (1) [>500]: regions accommodating large urban populations of more than 500000 people; (2) [250500]: regions with urban populations of more than 250000 people; (3) [100-250]: regions with urban populations between 100000 and 250000 residents; and finally (4) $[<100]$ : regions with urban population of less than 100000 people. This categorization is comparable with the administrative definition of large, medium, and small cities, which follows the same pattern.

The other part of the second objective is to analyze the effects of the regional area. Again the areas are divided into four categories; (1) [>12000]: regions with an area of more than $12000 \mathrm{~km} 2$; (2) [5000-12000]: regions with an area of between 5000 and 12000 
km2; (3) [2000-5000]: regions with an area of between 2000 and $5000 \mathrm{~km} 2$; and finally (4) $[<2000]$ : regions with an area of less than $2000 \mathrm{~km} 2$. This categorization is arranged so that a reasonable number of regions are included in every category.

A trustable statistical approach is needed to compare the mean annual transport energy consumption per capita of the categories explained above. A primary method can be Analysis of Variance (ANOVA), whose basic assumption is that the categories compared are normal distributions. To check this, conducting an AndersonDarling normality test is employed. This test is applied via calculating AD (Anderson-Darling) according to (1). The null hypothesis is that the populations and areas are normally distributed within the sample. In case of urban populations, the results of Anderson-Darling shows that the only category which is normally distributed is $[<100](\mathrm{AD}=0.6535$, $\mathrm{p}$-value $=0.0837)$. The other three categories do not enjoy normality (AD: [>500]: 3.132, [250-500]: 1.8579, [100-250]: 0.9177; p-values: [>500]: $<0.0005$, [250-500]: $<0.0005$, and [100250]: 0.0185). Three out of four categories are not normal distributions, so the null hypothesis is rejected.

Similarly the normality of the four area categories are tested by means of AndersonDarling test. The results show that only the regions having an area of between 5000 and $12000 \mathrm{~km} 2$ are normally distributed $(\mathrm{AD}=0.6495$, $\mathrm{p}$-value $=0.08)$. The other area categories are not normal (AD: [>12000]: 4.9017, [2000-5000]: 5.3779, [<2000]: 6.6863 ; p-value: $[>12000]:<0.0005,[2000-$ 5000]: $<0.0005$, and $[<2000]:<0.0005)$. Again the null hypothesis of normality is rejected for three of the categories. Since the goal is to make two-by-two comparisons, all the categories should be normal to make ANOVA. As a result, a nonparametric mean analysis is better to be taken to compare the means of both populations and areas (Eq. (1)).

$A D=-N-\frac{2 i-1}{N}\left(\ln \left(F\left(Y_{i}\right)\right)+\ln \left(1-F\left(Y_{N+1-i}\right)\right)\right)$

Whereas:

$F$ : The cumulative distribution function of the specified distribution;

$Y i$ : The ordered data;

$N$ : The total number of observations.

A suitable nonparametric mean analysis method is Kruskal-Wallis which is applied to show the significance of differences in the average fuel use in the four urban population and area categories. There is no normality assumption for applying this method. The analysis is undertaken via Eq. (2). Since it is not possible to conduct this test among all the groups, the comparison must be done between every two categories.

$$
K=(N-1) \frac{\sum_{i=1}^{g} n_{i}\left(\bar{r}_{i}-\bar{r}\right)^{2}}{\sum_{i=1}^{g} \sum_{j=1}^{n_{i}}\left(r_{j}-\bar{r}\right)^{2}}
$$

\section{Where:}

$n_{i}$ : Number of observations in group $i$;

$r_{i j}$ : The rank of observation $j$;

$\mathrm{N}$ : The total number of observations in all groups.

\section{Findings}

The study results are arranged to give explanations for fulfilling the two objectives of the study about the roles of urban population density, population size, and regional area in explaining fuel use. The 
first step is to study the general form of the population density and energy use diagram. The same approach that Newman and Kenworthy took to show the relationships in the world cities is applied to test the correlations in the regions. Fig. 5 (left) shows how the two parameters interact with each other. Although there is a general negative relationship between the parameters, but the resulted logarithmic R-squared is weak (0.029). Having an impression about the location of each population size category in the diagram can be more informative. The right diagram of Fig. 5 illustrates the situation of the regions of the four population size categories. The same observation about the population size categories also shows small correlations (Fig. 6). Regions with urban populations more than 100000 inhabitants have R-squared near to zero. The only correlation that is observed is about regions with population less than 100000 people (R-squared=0.079). Although these figures give a general understanding of the subject, but more precise analysis is needed to show the possible effectiveness of population size and area. Statistical analysis can provide the needed output about meaningful comparisons between the categories. Fig. 6 takes four different categories as below: regions with a population more than 500000 inhabitants (top-left), regions with a population between 250000 and 500000 people (top-right), regions with a population of between 100000 and 250000 people (bottom-left), and finally regions with a population less than 100000 inhabitants (bottom-right).
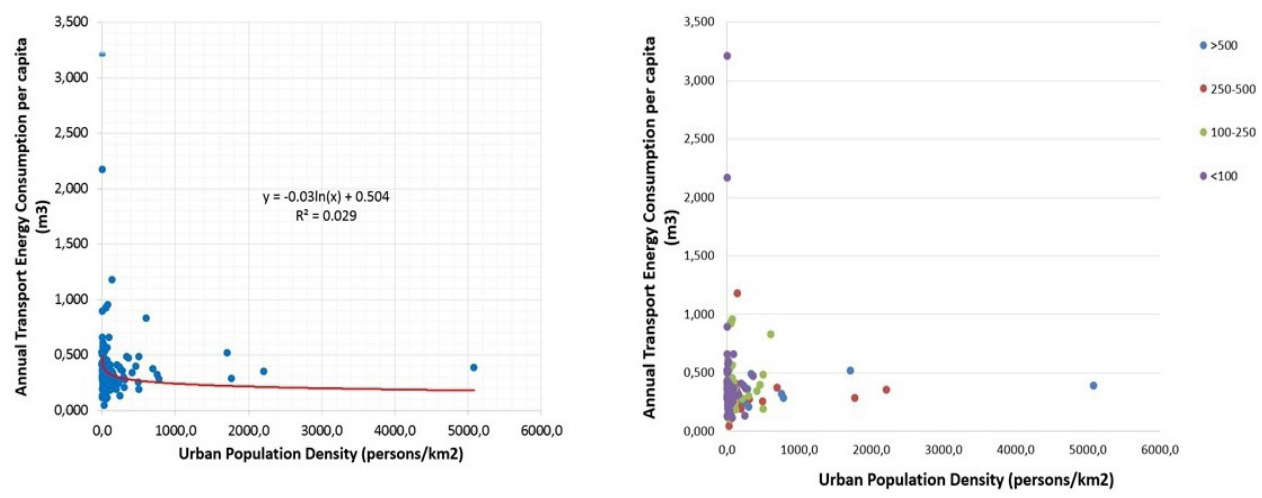

Fig. 5.

General Relationship between Annual Transport Energy Consumption and Urban Population Density

To do this, a statistical comparisons between categories made based on urban population size and regional area are undertaken. The average energy use in the selected population categories are shown in Table 2. This table illustrates the descriptive statistical analysis of the four categories based on urban population density and regional area. As mentioned in the methodology section,
Kruskal-Wallis method is applied because 3 out of 4 in both population and area categories are non-normal. Kruksal-Wallis only conducts two-by-two nonparametric mean comparisons. Therefore the means of energy use in the selected categories are compared to each other in a two-by-two manner and the significance of the mean differences are indicated. The results of 
this experiment are shown in Table 3. The findings show that there are significant or marginally significant differences in transport energy consumption between large metropolitan regions of more than 500000 inhabitants and small populations of less than 100000 people on the one hand and populations of between 100000 and 500000 people on the other hand. According to this table, large metropolitan areas and small settlements of less than 100000 urban
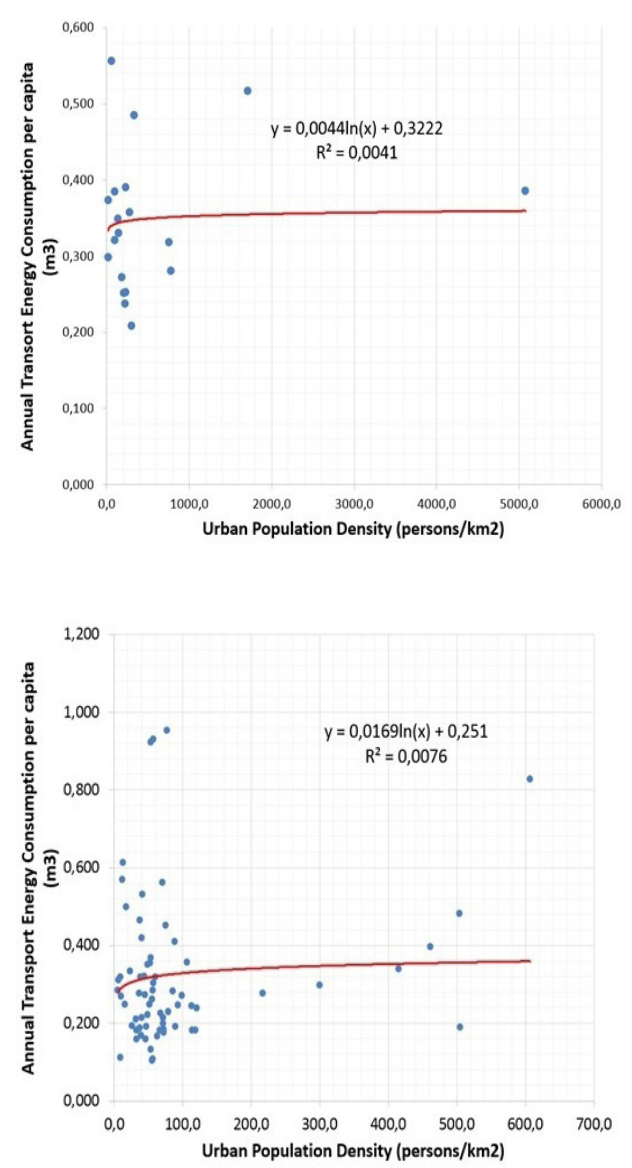

dwellers use more energy for their mobility than that of regions with medium population. Regional area also seems to be crucial in defining energy use pattern. Large regions with more than 12000 square kilometers use significantly more transport energy than 5000 square kilometers. Moreover, regions with areas less than 2000 square kilometers consume more transport fuel than regions with areas between 2000 and 5000 square kilometers.
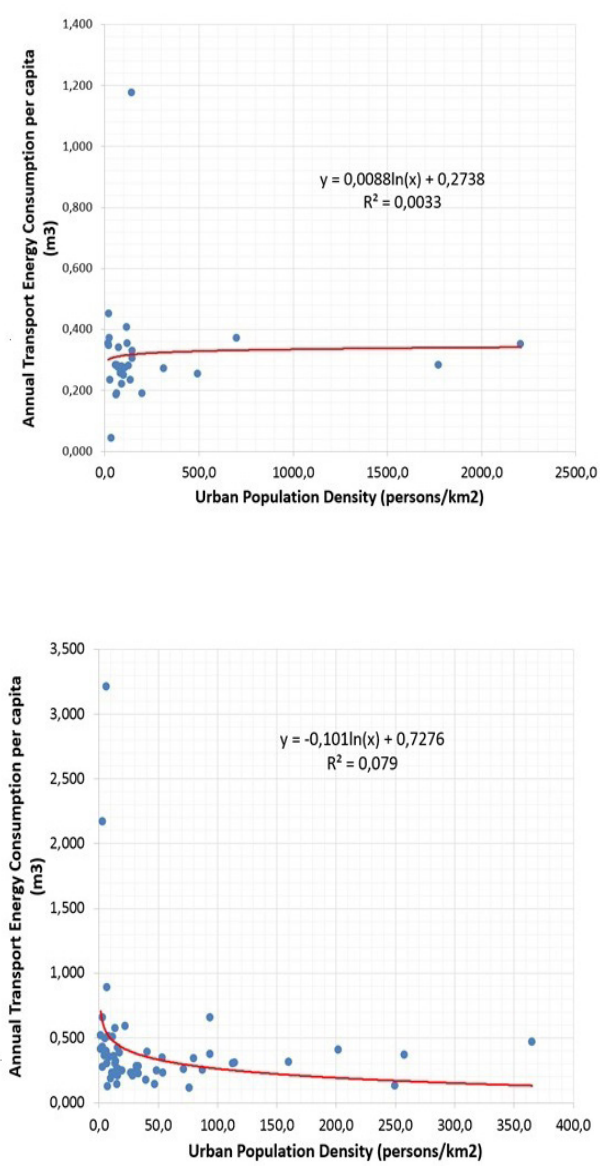

Fig. 6.

Correlations between Urban Population Density and Annual Transport Energy Consumption per Capita 
Table 2

Sample Descriptive Stats of the Four Study Categories Concerning "Urban Population Density" and "Regional Area"

\begin{tabular}{|c|c|c|c|c|c|c|c|c|c|c|c|}
\hline \multicolumn{6}{|l|}{ Urban Population } & \multicolumn{6}{|l|}{ Regional Area } \\
\hline Stat. & No & Average & Min & Max & St. Dev. & & No & Average & Min & Max & St. Dev. \\
\hline $\begin{array}{l}\text { More than } \\
500000 \\
\text { inhabitants }\end{array}$ & & & & & & $\begin{array}{l}\text { More than } 12000 \\
\mathrm{~km}^{2}\end{array}$ & & & & & \\
\hline Population & & 1446351 & 526294 & 8293140 & 1791639 & Population & & 335765 & 38077 & 2174172 & 475621 \\
\hline Area $\left(\mathrm{km}^{2}\right)$ & & 9012 & 365 & 44630 & 11913 & Area $\left(\mathrm{km}^{2}\right)$ & & 21061 & 11526 & 55808 & 12276 \\
\hline $\begin{array}{l}\text { Urban population } \\
\text { density (per/ha) }\end{array}$ & 19 & 573 & 16,2 & 5078,4 & 1160 & $\begin{array}{l}\text { Urban population } \\
\text { density }(\mathrm{per} / \mathrm{ha})\end{array}$ & 23 & 19,9 & 1,24 & 138,4 & 32 \\
\hline $\begin{array}{l}\text { Transport energy } \\
\text { use }\left(\mathrm{m}^{3}\right)\end{array}$ & & 525412 & 109457 & 3201230 & 719736 & $\begin{array}{l}\text { Transport energy } \\
\text { use }\left(\mathrm{m}^{3}\right)\end{array}$ & & 128610 & 10440 & 759193 & 166862 \\
\hline $\begin{array}{l}\text { Transport energy } \\
\text { use per year per } \\
\text { capita }\left(\mathrm{m}^{3}\right)\end{array}$ & & 0,346 & 0,208 & 0,485 & 0,094 & $\begin{array}{l}\text { Transport energy } \\
\text { use per year per } \\
\text { capita }\left(\mathrm{m}^{3}\right)\end{array}$ & & 0,494 & 0,111 & 3,210 & 0,607 \\
\hline $\begin{array}{l}\text { Between } 250000 \\
\text { and } 500000 \\
\text { inhabitants }\end{array}$ & & & & & & $\begin{array}{l}\text { Between } 5000 \\
\text { and } 12000 \mathrm{~km}^{2}\end{array}$ & & & & & \\
\hline Population & & 341590 & 254704 & $3,2 \mathrm{E}+12$ & 79750 & Population & & 408608 & 41876 & 1700687 & 662992 \\
\hline Area $\left(\mathrm{km}^{2}\right)$ & & 4794 & 176 & 141908127 & 3944 & Area $\left(\mathrm{km}^{2}\right)$ & & 6699 & 5071 & 11141 & 1721 \\
\hline $\begin{array}{l}\text { Urban population } \\
\text { density ( } \mathrm{per} / \mathrm{ha})\end{array}$ & 30 & 254 & 19,7 & 1346360 & 496 & $\begin{array}{l}\text { Urban population } \\
\text { density (per/ha) }\end{array}$ & 28 & 60,2 & 4,7 & 281,1 & 85,6 \\
\hline $\begin{array}{l}\text { Transport energy } \\
\text { use }\left(\mathrm{m}^{3}\right)\end{array}$ & & 106833 & 12307 & $5,2 \mathrm{E}+11$ & 61035 & $\begin{array}{l}\text { Transport energy } \\
\text { use }\left(\mathrm{m}^{3}\right)\end{array}$ & & 140339 & 12307 & 607255 & 294535 \\
\hline $\begin{array}{l}\text { Transport energy } \\
\text { use per year per } \\
\text { capita }\left(\mathrm{m}^{3}\right)\end{array}$ & & 0,315 & 0,043 & 1,177 & 0,181 & $\begin{array}{l}\text { Transport energy } \\
\text { use per year per } \\
\text { capita }\left(\mathrm{m}^{3}\right)\end{array}$ & & 0,336 & 0,043 & 0,891 & 0,166 \\
\hline $\begin{array}{l}\text { Urban } \\
\text { population } \\
\text { between } 10000 \\
\text { and } 250000\end{array}$ & & & & & & $\begin{array}{l}\text { Between } 2000 \\
\text { and } 5000 \mathrm{~km} 2\end{array}$ & & & & & \\
\hline Population & & 162819 & 100690 & 247681 & 41359 & Population & & 245690 & 21721 & 1695094 & 241599 \\
\hline Area $\left(\mathrm{km}^{2}\right)$ & & 4879 & 246,5 & 43405 & 6877 & Area $\left(\mathrm{km}^{2}\right)$ & & 3226 & 2109 & 5905 & 879 \\
\hline $\begin{array}{l}\text { Urban population } \\
\text { density (per/ha) }\end{array}$ & 68 & 93 & 5,6 & 606,5 & 124,7 & $\begin{array}{l}\text { Urban population } \\
\text { density (per/ha) }\end{array}$ & 60 & 83,1 & 9,7 & 782,1 & 104,9 \\
\hline $\begin{array}{l}\text { Transport energy } \\
\text { use }\left(\mathrm{m}^{3}\right)\end{array}$ & & 50865 & 15643 & 195781 & 32027 & $\begin{array}{l}\text { Transport energy } \\
\text { use }\left(\mathrm{m}^{3}\right)\end{array}$ & & 73894 & 4069 & 476399 & 83974 \\
\hline $\begin{array}{l}\text { Transport energy } \\
\text { use per year per } \\
\text { capita }\left(\mathrm{m}^{3}\right)\end{array}$ & & 0,319 & 0,104 & 0,953 & 0,188 & $\begin{array}{l}\text { Transport energy } \\
\text { use per year per } \\
\text { capita }\left(\mathrm{m}^{3}\right)\end{array}$ & & 0,294 & 0,104 & 1,177 & 0,171 \\
\hline $\begin{array}{l}\text { Urban } \\
\text { population less } \\
\text { than } 100000\end{array}$ & & & & & & $\begin{array}{l}\text { Less than } 2000 \\
\text { km2 }\end{array}$ & & & & & \\
\hline Population & & 61809 & 5263 & 98188 & 23797 & Population & & 296228 & 5263 & 8293140 & 1046119 \\
\hline Area $\left(\mathrm{km}^{2}\right)$ & & 5558 & 69 & 55808 & 8562 & Area $\left(\mathrm{km}^{2}\right)$ & & 1564 & 69 & 10360 & 1877 \\
\hline $\begin{array}{l}\text { Urban population } \\
\text { density (per/ha) }\end{array}$ & 57 & 48,4 & 1,2 & 365,4 & 71,6 & $\begin{array}{l}\text { Urban population } \\
\text { density (per/ha) }\end{array}$ & 62 & 329,3 & 2,9 & 5078,5 & 741 \\
\hline $\begin{array}{l}\text { Transport energy } \\
\text { use }\left(\mathrm{m}^{3}\right)\end{array}$ & & 26084 & 589 & 290520 & 37550 & $\begin{array}{l}\text { Transport energy } \\
\text { use }\left(\mathrm{m}^{3}\right)\end{array}$ & & 109757 & 589 & 3201230 & 404988 \\
\hline $\begin{array}{l}\text { Transport energy } \\
\text { use per year per } \\
\text { capita }\left(\mathrm{m}^{3}\right)\end{array}$ & & 0,418 & 0,112 & 3,210 & 0,472 & $\begin{array}{l}\text { Transport energy } \\
\text { use per year per } \\
\text { capita }\left(\mathrm{m}^{3}\right)\end{array}$ & & 0,371 & 0,112 & 2,17 & 0,287 \\
\hline
\end{tabular}


Table 3

Kruskal-Wallis Test for Categories Related to Urban Population Density and Region Area

\begin{tabular}{|c|c|c|c|c|c|c|c|c|c|}
\hline \multicolumn{5}{|c|}{ Urban Population } & \multicolumn{5}{|l|}{ Regional Area } \\
\hline $\begin{array}{l}\text { Urban } \\
\text { Population } \\
\text { Categories }\end{array}$ & 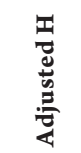 & d.f. & P-value & $\begin{array}{l}\text { Observation } \\
\text { Result }\end{array}$ & $\begin{array}{l}\text { Region Area } \\
\text { Categories }\end{array}$ & 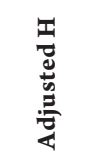 & d.f. & P-value & $\begin{array}{l}\text { Observation } \\
\text { Result }\end{array}$ \\
\hline $\begin{array}{l}{[>500] \leftrightarrow} \\
{[250-500]}\end{array}$ & 2.971 & 1 & $0.085^{* * *}$ & $\begin{array}{l}{[>500]>[250-} \\
500]\end{array}$ & $\begin{array}{l}{[>12000] \leftrightarrow} \\
{[5000-12000]}\end{array}$ & 1.858 & 1 & 0.173 & $\begin{array}{l}{[>12000]=} \\
{[5000-12000]}\end{array}$ \\
\hline $\begin{array}{l}{[>500] \leftrightarrow} \\
{[100-250]}\end{array}$ & 4.436 & 1 & $0.035^{* *}$ & $\begin{array}{l}{[>500]>[100-} \\
250]\end{array}$ & $\begin{array}{l}{[>12000] \leftrightarrow} \\
{[2000-5000]}\end{array}$ & 12.465 & 1 & $0.0004^{*}$ & $\begin{array}{l}{[>12000]>} \\
{[2000-5000]}\end{array}$ \\
\hline $\begin{array}{l}{[>500] \leftrightarrow} \\
{[<100]}\end{array}$ & 0.367 & 1 & 0.545 & $\begin{array}{l}{[>500]=} \\
{[<100]}\end{array}$ & $\begin{array}{l}{[>12000] \leftrightarrow} \\
{[<2000]}\end{array}$ & 3.349 & 1 & $0.067^{* * *}$ & $\begin{array}{l}{[>12000]>} \\
{[<2000]}\end{array}$ \\
\hline $\begin{array}{l}{[250-500]} \\
\leftrightarrow[100- \\
250]\end{array}$ & 0.655 & 1 & 0.418 & $\begin{array}{l}{[250-500]=} \\
{[100-250]}\end{array}$ & $\begin{array}{l}{[5000-12000]} \\
\leftrightarrow[2000- \\
5000]\end{array}$ & 2.347 & 1 & 0.126 & $\begin{array}{l}{[5000-12000]=} \\
{[2000-5000]}\end{array}$ \\
\hline $\begin{array}{l}{[250-500]} \\
\leftrightarrow[<100]\end{array}$ & 0.947 & 1 & 0.33 & $\begin{array}{l}{[250-500]=} \\
{[<100]}\end{array}$ & $\begin{array}{l}{[5000-12000]} \\
\leftrightarrow[<2000]\end{array}$ & 0.019 & 1 & 0.889 & $\begin{array}{l}{[5000-12000]=} \\
{[<2000]}\end{array}$ \\
\hline $\begin{array}{l}{[100-250]} \\
\leftrightarrow[<100]\end{array}$ & 3.079 & 1 & $0.079^{* * *}$ & $\begin{array}{l}{[100-250]<} \\
{[<100]}\end{array}$ & $\begin{array}{l}{[2000-5000]} \\
\leftrightarrow[<2000]\end{array}$ & 5.598 & 1 & $0.018^{* *}$ & $\begin{array}{l}{[2000-5000]<} \\
{[<2000]}\end{array}$ \\
\hline
\end{tabular}

${ }^{*}$ Significant at 0.01 level

** Significant at 0.05 level

***Significant at 0.1 level

\section{Discussion}

This study shows that the association between population density and transport energy consumption in the regional level is weak. This finding is in contrast with a large number of metropolitan level findings that confirm this relation. In the metropolitan level, there have been new calls in the scientific community not to limit the studies to density, but to pay attention to a large variety of factors including socioeconomic, demographic, as well as geographic determinants of greenhouse gas production and energy consumption (for example: Baur et al., 2013). Here, population size and area are discussed on as effective indicators of energy use in the regions. Most of the studies about population size have been done on city level while this study focuses on the regional patterns of energy use. The mechanism that this paper finds is not in line with the citylevel findings of Newman and Kenworthy (1989) and Naess and his colleagues (1996) who concluded that city size was not a predictor of energy use, while it confirms the conclusion of Hughes et al. (2004).

According to the findings of this study, transport fuel use varies in regions with different populations and areas. Such differences are significant in case of comparisons between large populations or areas with middle-sized ones. The summarization of the mean comparisons based on urban population and area (Fig. 7), indicates that vast regions accommodating large populations show weaker energy efficiency than medium regions with medium populations. Similarly low-populated small regions have the same failure compared to mid-sized regions. 
These findings relatively confirm the pattern that Owens (1986) showed in her research. According to her, higher energy use is observed in Greater London, small urban areas, and non-urban areas while provincial conurbations and large urban areas have the lowest energy use, but the difference is that the Iranian experience shows that the regions which produce energy efficient patterns are still smaller than what Owens found. The idea of inefficiency in energy patterns of small towns has also been confirmed by Banister et al. (1997) who noted high energy use of residential population sizes of more than 25000 people.

The interesting point seen in the practice done in this study is high energy use by transportation-related activities in lowpopulated areas, which can theoretically be connected to urban sprawl. There are evidences that show urban sprawl is associated with high city-wide transport energy use (Holden and Norland, 2005). It has also been shown that many Iranian metropolitan areas as well as medium and large cities are sprawling (Masoumi, 2012; Masoumi, 2014). But very little evidence has been gathered about sprawl in small cities and low-populated regions so that a basic understanding of the causes of high energy use is resulted. It is likely that weak public transport infrastructure in those areas persuade residents to use personal cars as the only trustable transport mode, while sprawling areas have made travel destinations far away. However more in-depth research is needed to study the associations between regional-level transport fuel use and urban sprawl. Such approaches are usually difficult to develop because of lack of accessibility to travel data. It has been shown in case of the US that suburbanization and sprawling of jobs can lead to shortening of travel distances
(Crane and Chatman, 2003). But there is no evidence of job suburbanization in Iranian cities. It seems that Iranian cities are still continuing their growth with a dominant monocentric form. This will result in producing long urban travels and higher energy consumption.

The relative appropriateness of mid-sized regions is shown as one of the results of this study. These cities provide suitable population size together with more accessible destinations compared to metropolitan areas, small towns, and rural places. Therefore it is not surprising that they resulted in less energy use.

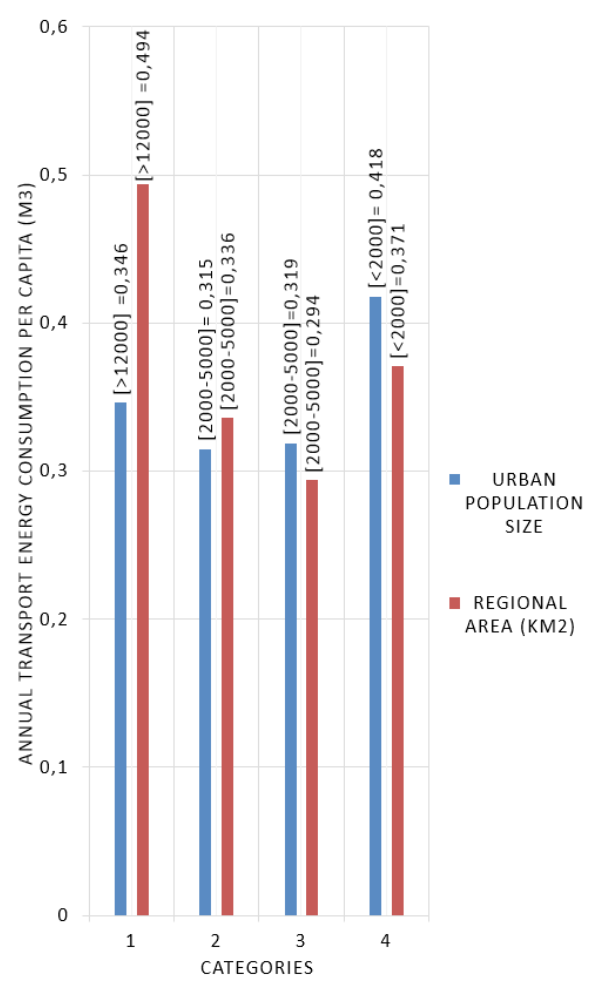

Fig. 7.

Mean Comparisons Results of 174 Iranian

Regions Categorized 


\section{Conclusion}

The weak associations between urban population density and energy consumption in the regional level observed in this study is in contrast with the previous findings that demonstrated considerable associations between these two factors. Although urban level seems important for urban planning, but regional level provides a holistic perspective to energy use. Trade-offs between these two levels of energy research can be a topic for future research.

Mid-sized urban areas located in regions show good potentials for providing energyefficient patterns. Many urban challenges of the megacities have been focused during the past years, but the unsustainable side of the small towns and rural areas has received less attention. It is noteworthy to mention that sustainable urban forms are not only a complementary solution for energy problem in large metropolitan areas, but it should not be neglected in case of small towns. Traffic congestion problems are less visible in these areas, but it does not necessarily mean that the small towns are more energy-efficient.

Finally, the connections between urban sprawl and transport energy consumption are not yet completely known. This sort coming is obvious in the context of developing countries. Demonstration of temporal associations between sprawl and transport fuel use would be a useful achievement of the future studies.

\section{References}

Banister, D.; Watson, S.; Wood, C. 1997. Sustainable Cities, Transport, Energy and Urban Form, Environment and Planning B: Planning and Design, 24(1): 125-143.

Baur, A.H.; Thess, M.; Kleinschmit, B.; Creutzig, F. 2013. Urban Climate Change Mitigation in Europe: Looking at and beyond the Role of Population Density, Journal of Urban Planning and Development. DOI: http:// dx.doi.org/10.1061/(ASCE)UP.1943-5444.0000165, 140(1): 040130031-0401300312.

Bourdic, L.; Salat, S. 2011. Urban Density and Private Transport Energy Consumption: a Fractal Model. In Proceedings of the $16^{\text {th }}$ International Conference of Hong Kong Society for Transportation Studies, 17-20 December 2011, Hong Kong.

Breheny, M. 1995. The Compact City and Transport Energy Consumption, Transactions of the Institute of British Geographers. DOI: http://dx.doi.org/10.2307/622726, 20(1): 81-101.

Brindle, R.E. 1994. Lies, Damned Lies and "Automobile Dependence" - Some Hyperbolic Reflections. In Proceedings of the 1994 Australian Transport Research Forum, Melbourne, Australia. 117-131.

Commission of European Communities. 1990. Green Paper on the Urban Environment. European Commission, Brussels.

Crane, R.; Chatman, D.G. 2003. Traffic and Sprawl: Evidence from US Commuting, 1985 to 1997, Planning \& Markets, 6(1): 14-22. 
Department of the Environment. 1990. This Common Interitance. HMSO, London.

Department of the Environment. 1992. Development Plans and Regional Planning Guidance. PPG12, HMSO, London.

Department of the Environment. 1993. Sustainable Development: the UKStrategy. Cmnd 2426 HMSO, London.

Department of the Environment. 1994. Transport PPG13 HMSO, London.

Evill, B. 1995. Population, Urban Density and Fuel Use: Eliminating the Spurious Correlation, Urban Policy and Research. DOI: http://dx.doi. org/10.1080/08111149508551669, 13(1): 29-36.

Gomez-Ibanez, J.A. 1991. A Global View of Automobile Dependence, Journal of American Planning Association, 57: 376-379.

Gordon, P.; Rishardson, H.W. 1989. Gasoline Consumption and Cities: A Reply, Journal of American Planning Association. DOI: http://dx.doi. org/10.1080/01944368908975421, 55(3): 342-346.

Gilbert, R.; Pearl, A. 2010. Transport Revolutions. Moving People and Freight without Oil. Gabriola Island: New Societies Publishers.

Hester, R. 2006. Designing for Ecological Design. Cambridge: The MIT Press.

Holden, E.; Norland, I.T. 2005. Three Challenges for the Compact City as a Sustainable Urban Form: Household Consumption of Energy and Transport in Eight Residential Areas in the Greater Oslo Region, Urban Studies. DOI: http://dx.doi. org/10.1080/00420980500332064, 42(12): 21452166.

Hughes, B.; Chambers, L.; Lansdell, H.; White, R. 2004. Cities, Area and Transport Energy, Road Transportation Research Journal, 13(2): 72-84.
Kenworthy, J.R.; Laube, F.B. 1999a. An International Sourcebook of Automobile Dependence in Cities 1960-1990. University Press of Colorado.

Kenworthy, J.R.; Laube, F.B. 1999b. Patterns of Automobile Dependence in Cities: an International Overview of Key Physical and Economic Dimentions with some Implications for Urban Policy, Transportation Research Part A, 33(1999): 691-723.

Kirwan, R. 1992. Urban Form, Energy and Transport: A Note on the Newman-Kenworthy Thesis, Urban Policy and Research. DOI: http://dx.doi. org/10.1080/08111149208551480, 10(1): 6-22.

Masoumi, H.E. 2012. Urban Sprawl in Iranian Cities and its Difference with the Western Sprawl, Spatium International Review, 27: 12-18.

Masoumi, H.E. 2014. Urban Sprawl in Mid-sized Cities of MENA, Evidence from Yazd and Kashan in Central Iran, Management Research and Practice, 6(2): 25-41.

Naess, P. 1993. Transportation Energy in Swedish Towns and Regions, Scandinavian Housing and Planning Research. DOI: http://dx.doi.org/10.1080/02815739308730340, 10(4): 187-206.

Naess, P. 1995. Urban Form and Energy Use for Transport: A Nordic Experience. $\mathrm{PhD}$ dissertation. Norwegian Institute of Technology.

Naess, P.; Sandberg, S.L.; Roe, P.G. 1996. Energy Use for Transportation in 22 Nordic Towns, Scandinavian Housing \& Planning Research. DOI: http://dx.doi. org/10.1080/02815739608730401, 13(2): 79-97.

Nakamura, R.; Horiike, T. 2002. Effects of Urban Form and Urban Planning on Household Gasoline Consumption by City, City Planning Review, 235: 54-64.

National Physical Planning Agency. 1991. Summary of the Fourth Report Extra on Physical Planning. Ministry of Housing, Physical Planning and Environment, The Hague. 
Neuman, M. 2005. The Compact City Fallacy, Journal of Planning Education and Research. DOI: http://dx.doi. org/10.1177/0739456X04270466, 25(1): 11-26.

Newman, P.; Kenworthy, J. 1989. Cities and Automobile Dependence, an International Sourcebook. Gower Publishing Co., England.

Ogawa, M.; Yamada, H. 2002. Urban Structure, Automobile Use and Gasoline Consumption, Expressway and Automobiles, 45(10): 27-36.

Owens, S. 1986. Energy Planning and Urban Form. London: Pion. 